\title{
Structural appraisal of existing masonry quadripartite vaults
}

Michelle Hicks MEng

Assistant Engineer, WSP, London, UK
Juan Sagaseta Eur Ing, PhD, DIC, CEng, MICE, MCICCP

Lecturer, Department of Civil and Environmental Engineering, University of Surrey, Guildford, UK (corresponding author: j.sagaseta@surrey.ac.uk)

\begin{abstract}
Quadripartite vaults are found in many historic buildings and are often below ground level. When new infrastructure is developed above these structures it is necessary to assess the strength of the existing vaults. A new formula for assessing the failure load of quadripartite masonry vaults under uniform loads is presented. The approach is based on the upper-bound solution from limit analysis of the elliptical arch defined at the intersection between the cylindrical surfaces. The predictions from the analytical solution are consistent with numerical results from a symmetrical threedimensional finite-element (FE) analysis developed using a damage-plasticity model with homogeneous material properties for the masonry. A case study on the quadripartite vaults in the undercroft of London Bridge station is also presented. This case study is used to examine the effect of the presence of ribs and horizontal movement restraint introduced by surrounding structures. The presence of ribs was found to have the largest effect on the strength of the vault. The non-linear FE analysis showed that modifying the boundary conditions to restrain the edges of the vault from horizontal movement increased the failure load by approximately $30 \%$ for a vault without ribs. When ribs were included, the introduction of horizontal restraint had a much larger impact; in such cases a more refined model that explicitly includes the surrounding structure may be needed.
\end{abstract}

\author{
Notation \\ d depth of the intersection between brickwork \\ quadrants \\ $d_{\mathrm{c}}, d_{\mathrm{t}} \quad$ damage variables \\ $f_{\mathrm{b}} \quad$ normalised mean compressive strength of brick units \\ $f_{\mathrm{c}} \quad$ ultimate compressive strength \\ $f_{\text {cy }} \quad$ yield strength \\ $f_{\mathrm{k}} \quad$ characteristic compressive strength of masonry \\ $f_{\mathrm{m}} \quad$ compressive strength of mortar \\ $M_{\mathrm{P}} \quad$ moment required to cause plastic hinge \\ $N_{\theta} \quad$ hoop membrane force \\ w self-weight of the vault
}

\section{Introduction}

The advent of ribbed vaulting in the twelfth century was an important feature in the development of Gothic architecture, particularly in medieval churches and cathedrals. Pre-1200, sexpartite vaults were the configuration of choice for the main bays of large Gothic churches and cathedrals, after which quadripartite vaults became more common (Taylor, 1982). These structures are formed from two intersecting semi-cylinders, creating a structure formed of four quadrants with a square or rectangular view in plan. Several reasons have been suggested for the move from sexpartite to quadripartite vaulting, including constructability and the introduction of flying buttresses (Taylor, 1982). Regardless of the reason for the distinct change in the preferred style of vault post-1200, the quadripartite vault has withstood the test of time and can still be seen today in many medieval cathedrals and underground historic structures.

Nowadays, quadripartite vaults can be constructed from a variety of materials. The most traditional material is masonry, but examples of concrete, timber and steel quadripartite vaults can also be observed. An example of an interesting steel structure is the vaulted roof at Lisbon airport, where ribs are also utilised to carry the loads to the supports (Figure 1).

\section{Review of structural behaviour}

Quadripartite vaults remain in equilibrium by distributing applied loads through the masonry shell of the vault to the elliptical intersections between vault quadrants, which carry the load to the buttresses. The compressive stresses acting in the shell of the structure can be estimated by multiplying the radius of curvature of the shell by the unit weight of the material from which it is constructed. This generally produces very low stresses that do not cause problems even in poorquality mortar (Heyman, 1995). The highest stress concentrations are produced where two of the vault quadrants intersect and hence ribs are often used in these areas to strengthen the vault and avoid crack formation. The load distribution between the masonry shell and the ribs at the intersections will depend on the relative stiffness of these elements. For quadripartite vaults under a uniformly distributed load and symmetrical boundary conditions, the horizontal thrust from each quadrant will be in equilibrium and only the vertical thrust will be carried by the ribs. If the load acting over the vault is not uniform, the ribs will also carry horizontal thrusts. The soil-structure interaction between the masonry and backfill can also enhance the strength of the vault. A comprehensive review of analytical models of masonry cross-vaults without ribs was carried out by Milani et al. (2014).

A case study from a structure at London Bridge station is presented in this paper to illustrate the important role ribs play in 


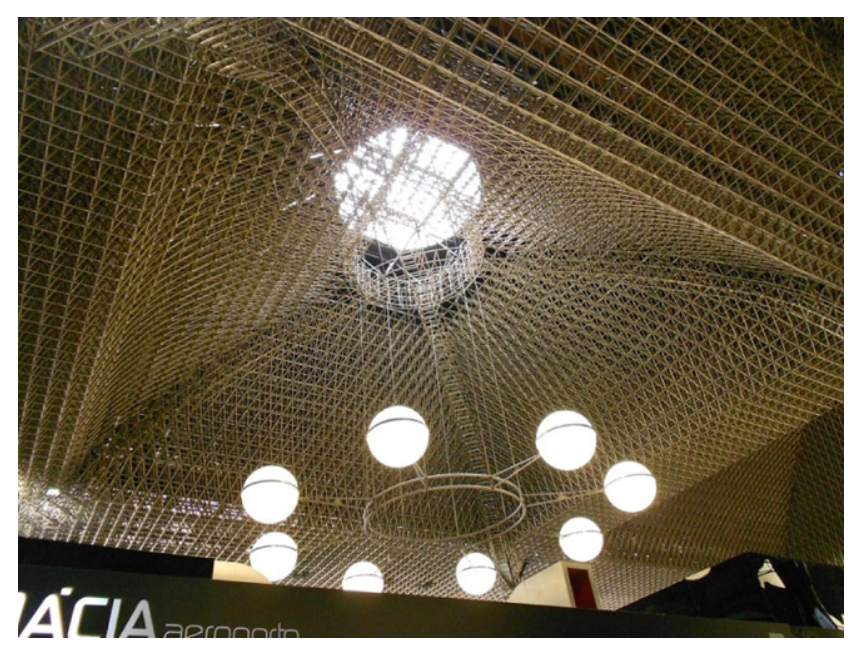

Figure 1. Steel space frame roof at Lisbon airport

the behaviour of quadripartite vaults as well as the influence of horizontal restraints from adjacent vaults. In addition, a new formula for assessing the failure load is presented for unrestrained cases based on limit analysis.

\section{Analysis of quadripartite vaults}

A useful overview of existing methods for the analysis of quadripartite vaults is given by Huerta (2008). Perhaps the most important development was the application of limit analysis to masonry arches by Heyman (1966).

\subsection{Limit analysis based on the lower-bound solution}

Limit analysis based on the lower-bound solution identifies possible lines of thrust that can be contained within an arch. The minimum arch thickness to ensure stability is that which only just contains the line of thrust. If the load is increased any further and the thrust line moves outside the thickness of the arch, a mechanism will form and the arch will collapse. The main challenge in the analysis of masonry arches is assessing the line of thrust that remains within the thickness of the masonry. Historically, the approach was to use the anti-funicular concept. Today, the application of structural analysis software can help determine the critical areas where hinge formation is most likely and further investigation is required. These critical areas can then be investigated in more depth using other methods such as the slicing method.

\subsection{The slicing method}

Slicing three-dimensional (3D) vaults into sections can enable the path of forces through the structure to be determined. For a ribbed quadripartite vault, these slices would be taken in the direction perpendicular to the cylinder axis, as shown in Figure 2(a) (O’Dwyer, 1999). For a cross-vault without ribs, a different load path may be considered where the load is completely carried by the masonry membrane, as shown in Figure 2(b) (Milani et al., 2014).

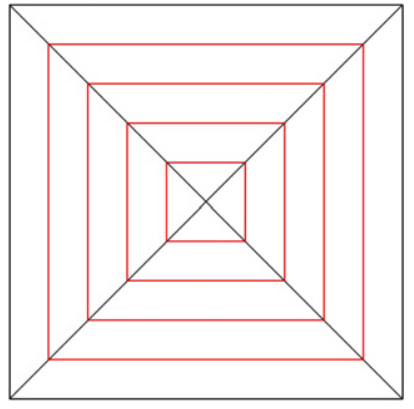

(a)

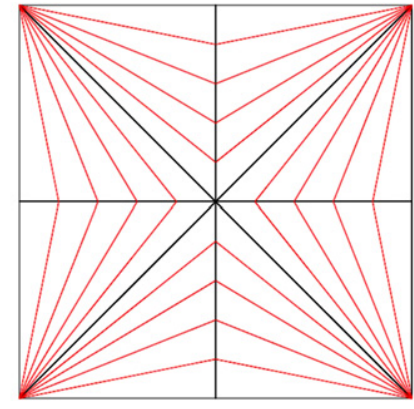

(b)
Figure 2. Slices taken for a ribbed vault (a) and a vault without ribs (b) (Milani et al., 2014; O'Dwyer, 1999)

The line of thrust acting in each slice will affect the forces acting in the ribs. Thus, one way to analyse a vault would be to use the slicing method to find the thrusts acting on the ribs from each slice before applying these loads to the ribs separately. This method does not take into account the interaction between adjacent slices in the structure but, since the rest of the structure would act to increase the strength of the slice being analysed, this method potentially produces 'safe' results. However, the slicing method can produce unreliable results in terms of the failure loads and mechanisms predicted because it does not take into account the biaxial stresses acting on the vault (Milani et al., 2014). In the study reported in this paper, a more sophisticated 3D finite-element (FE) analysis combined with membrane theory was used to investigate the behaviour of the vault.

\subsection{Membrane theory}

Heyman (1966) used the equations of equilibrium to determine the membrane forces acting on a single vault formed from two intersecting semi-cylindrical barrel vaults. Membrane theory assumes that the vault is very thin (only membrane forces are considered (i.e. hoop and axial membrane forces)), which is clearly not the case for some masonry structures. For a structure to be classed as a thin shell, the ratio of minimum radius of curvature to the thickness of the shell is normally greater than 20 (Heyman, 1995).

Resolving the forces acting in the circumferential direction leads to the result given in Equation 1 (Heyman, 1966), which can be used to calculate the hoop membrane force, $N_{\theta}$, acting on the vault, where $w$ is self-weight of the vault (in $\mathrm{kN} / \mathrm{m}^{2}$ ) and $a$ and $\theta$ are as defined in Figure 3.

1. $N_{\theta}=-w a \cdot \cos \theta$

Equation 1 only applies to a masonry vault with no ribs under uniformly distributed gravity loading. The boundary conditions at the edges of the vault will have a large impact on the 


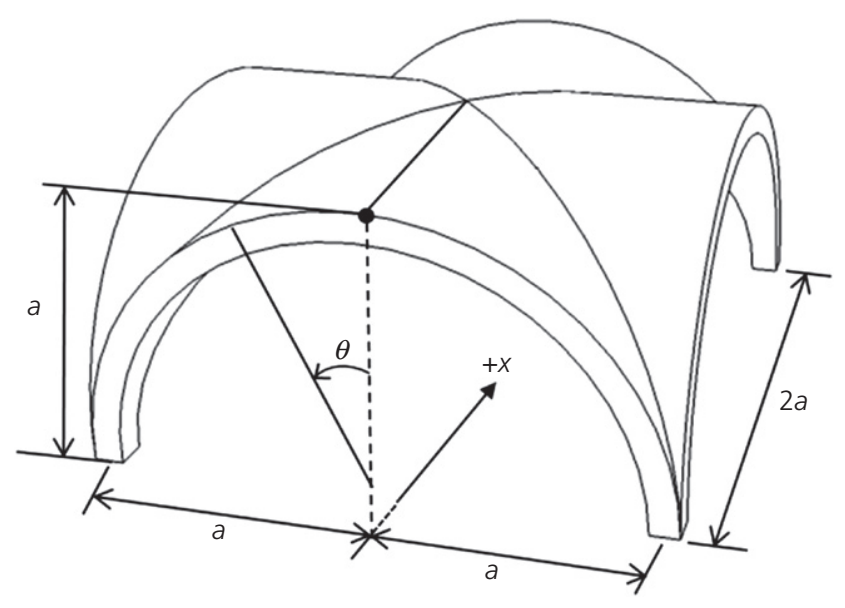

Figure 3. Sign conventions used in Heyman's membrane equations (Heyman, 1966, 1995)

observed stresses. In particular, the effect of any adjacent structures restraining horizontal movement is not taken into account in Equation 1, which assumes a single vault supported only at the base.

\subsection{Finite-element (FE) modelling}

Numerical modelling of masonry structures is commonly carried out by means of macro or micro models, depending on the level of detail in the study. Macro models, assuming a homogeneous material, are frequently used to model global behaviour due to their simplicity. Such approaches can produce reasonable predictions of test results, as shown by Creazza et al. (2000) among others. Alternatively, micro modelling can be used to model the mortar and individual units separately, although this is generally computationally demanding and only suited to detailed local problems (e.g. around openings). A macro model approach was adopted in this work to assess the global behaviour and the formation of plastic hinges in a quadripartite vault. The FE mesh in the 3D model used in this analysis is shown in Figure 4, which corresponds to a simply supported case. Shell elements were used in the developed FE models in order to simplify the analysis and frame elements were used only in some cases where rib members were present at the intersection of the cylindrical shells, as shown in Figure 4. The load considered was a uniformly distributed load applied to the shell elements in the direction of gravity.

\section{Case study: London Bridge station}

The redevelopment of London Bridge station is part of the Thameslink programme to increase the number and length of trains that can run on the line from Bedford to Brighton through central London. This work involves the construction of a new viaduct at London Bridge, which will significantly increase the load acting on a section of the existing quadripartite vaults, as shown in Table 1.

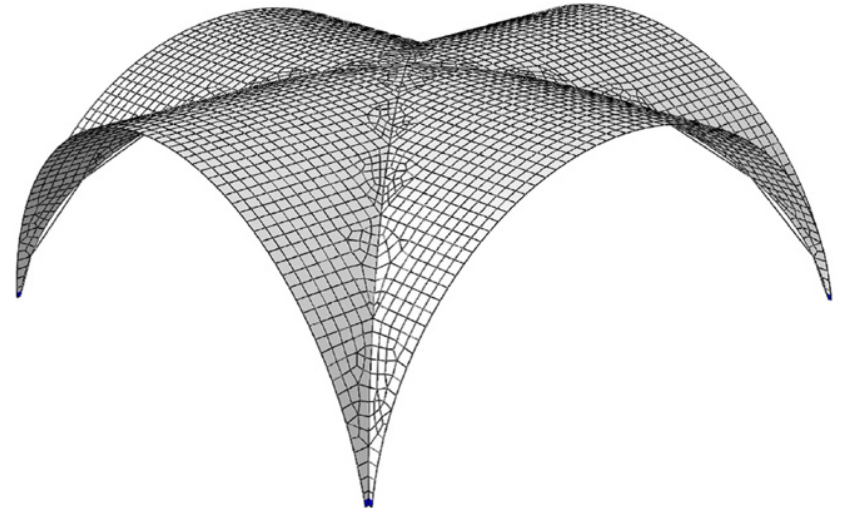

Figure 4. FE model developed in this work using 3D shell elements

Table 1. Design loads acting on vault

$\begin{array}{lr} & \text { Load: } \mathbf{k N} / \mathbf{m}^{\mathbf{2}} \\ \text { Brickwork self-weight } & 6 \cdot 9 \\ \text { Backfill self-weight } & 52 \cdot 9 \\ \text { Viaduct supports } & 17 \cdot 8 \\ \text { Concrete slab, ballast and sleepers } & 9 \cdot 4 \\ \text { Railway traffic } & 25 \cdot 1 \\ \text { Total } & 112 \cdot 2\end{array}$

The quadripartite vaults were constructed between 1839 and 1845 (Alan Baxter Ltd, 2011) from clay brickwork with blockwork forming the ribs between the vault quadrants, as can be seen in Figure 5. This case study is used as an example to show how the techniques presented in this paper can be used to determine the failure modes of an existing quadripartite vault.

The structural properties of these vaults were determined by in situ testing. In the analysis, a thickness of $330 \mathrm{~mm}$ was adopted for the brickwork and the ribs, although subsequent surveys showed that the thickness was actually around

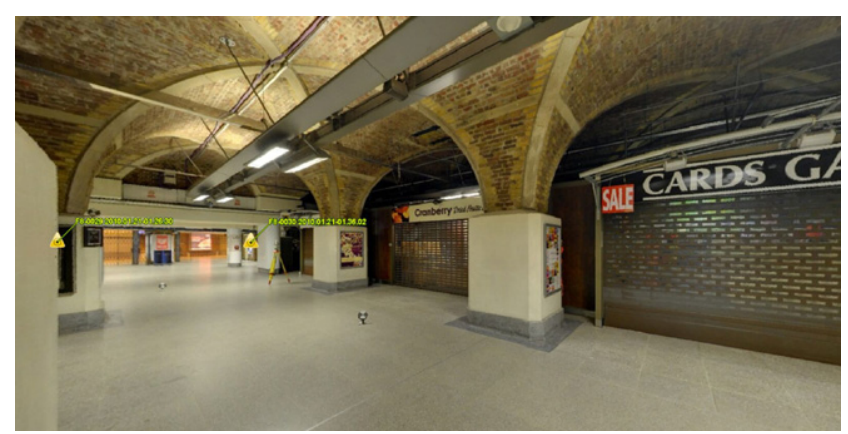

Figure 5. Small section of the quadripartite vaults at London Bridge station (courtesy Plowman Craven) 
$470 \mathrm{~mm}$. The geometry of the vaults was determined using 3D laser scanning to produce a point cloud survey. The geometry was simplified to allow comparison with the stresses predicted by Equation 1, which assumes that each vault quadrant is perfectly semi-cylindrical with a radius of $a$. Clearly this will not be the case for all vaults, as in this analysis where half of each vault span was equal to $2.74 \mathrm{~m}$ and the height was $2.30 \mathrm{~m}$. The average value of the vault height and half of the span were used to compare the results of the FE analysis with Equation 1 and the results of the limit analysis presented in Section 5.2, and so $a=2.52 \mathrm{~m}$.

The mechanical properties of the clay brickwork used in this analysis are presented in Table 2.

For an assessment of existing masonry structures, the compressive strength should ideally be found by in situ testing or core extraction. Where this is not feasible, brick and mortar samples should be taken from the structure and tests completed to determine the compressive strength of the masonry units and mortar. Eurocode 6 (BSI, 2009) provides a method for combining these properties to determine the characteristic compressive strength of the masonry, as given by

\section{2. $f_{\mathrm{k}}=K f_{\mathrm{b}}^{\alpha} f_{\mathrm{m}}^{\beta}$}

where $f_{\mathrm{m}}$ is the compressive strength of the mortar, $f_{\mathrm{b}}$ the normalised mean compressive strength of the brick units and $K, \alpha$ and $\beta$ are constants given in Eurocode 6 (BSI, 2009) for different types of mortar.

According to Eurocode 6, for masonry group 1 clay units with general-purpose mortar (as assumed in this case), $K=0.55$, $\alpha=0.7$ and $\beta=0.5$. The values of $f_{\mathrm{b}}$ and $f_{\mathrm{m}}$ were obtained in this project from samples taken at 30 different locations (Tony Gee and Partners, 2011). The values thus obtained were $5.46 \mathrm{MPa}$ and $2 \mathrm{MPa}$ for $f_{\mathrm{b}}$ and $f_{\mathrm{m}}$, respectively which leads to $f_{\mathrm{k}}=2 \cdot 22 \mathrm{MPa}$ according to Equation 2. However, the coefficient of variation of the samples was $0 \cdot 49$, which is larger than the permissible value of $0 \cdot 25$. Therefore, Annex D (design assisted by testing) of Eurocode 0 (BSI, 2002) was adopted in the project to derive a more refined statistical value of $f_{\mathrm{k}}$, as shown by Tony Gee and Partners (2011); a final value of $f_{\mathrm{k}}=1.88 \mathrm{MPa}$ was adopted. The Young's modulus listed in

Table 2. Mechanical properties of the brickwork adopted in the elastic FE model

\begin{tabular}{lr} 
Property & \\
\hline Thickness, $t$ & $330 \mathrm{~mm}$ \\
Young's modulus, $E$ & $1880 \mathrm{~N} / \mathrm{mm}^{2}$ \\
Density, $\rho$ & $15.6 \mathrm{kN} / \mathrm{m}^{3}$ \\
Compressive strength, $f_{\mathrm{c}}$ & $1.9 \mathrm{~N} / \mathrm{mm}^{2}$ \\
Poisson's ratio, $v$ & 0
\end{tabular}

Table 2 was taken as $K_{\mathrm{E}} f_{\mathrm{k}}$, where $K_{\mathrm{E}}$ is given as 1000 in clause NA.2.9 in the UK National Annex to Eurocode 6 (BSI, 2007).

\subsection{Preliminary analyses}

For the preliminary analysis of the existing structure, a 3D elastic FE model of a single vault was developed. The masonry was assumed to be a homogeneous material. The Poisson's ratio was set to zero for this preliminary analysis so that the results could be verified using Equation 1 from membrane theory. Since Equation 1 applies to a single vault, the restraining effect of the surrounding vaults was not included at this stage of the analysis so the vault was only supported at its base.

To allow a reasonable comparison between the results from the elastic FE model and the analytical equations provided in Section 3.3, the limestone ribs stiffening the vaults were not included at this stage. The membrane forces on the vault (hoop and axial) obtained from the elastic FE analysis are shown in Figure 6. The average hoop membrane force at the top of the cylindrical vault from $x=0$ to $x=a$ was approximately $300 \mathrm{kN} / \mathrm{m}$. Calculating the hoop membrane force using Heyman's formula (Equation 1) with $w=-112 \cdot 2 \mathrm{kN} / \mathrm{m}^{2}$ and $a=2.52 \mathrm{~m}$ gives $N_{\theta}=282 \mathrm{kN} / \mathrm{m}$. The results from the FE model therefore compare well with the results from Heyman's equation.

The lines of thrust through the edge of the vault quadrant at $x=0$ and the centre of the vault quadrant where $x=a / 2$ are drawn in Figure 7, which shows that, under the design load, failure does not occur in the cylindrical shell. The thrust line moves further away from the middle third where $\theta=70^{\circ}$ in Figure 7(a) and, to a more limited extent, where $\theta=35^{\circ}$ in Figure 7(b). These areas are close to the elliptical intersections between vault quadrants, suggesting that hinge formation starts around these areas. Foraboschi (2004) demonstrated

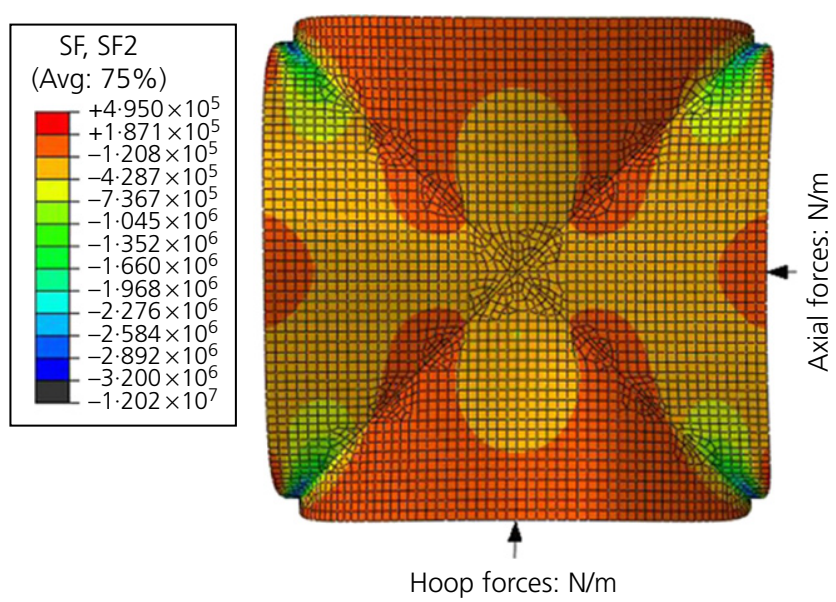

Figure 6. Membrane forces obtained in the elastic analysis with uniformly distributed loads. A full-colour version of this figure can be found on the ICE Virtual Library (www.icevirtuallibrary.com) 


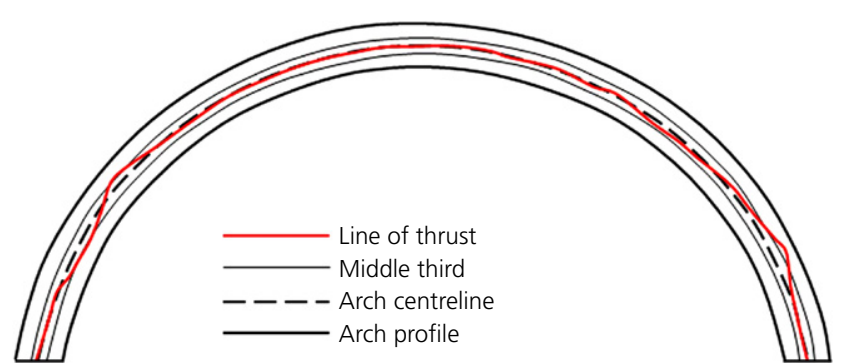

(a)

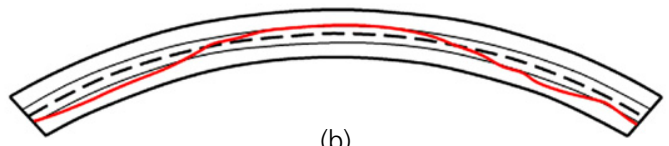

(b)

Figure 7. Line of thrust at (a) $x=0$ and (b) $x=a / 2$

experimentally that strengthening the elliptical intersections with fibre-reinforced polymer strips significantly enhances the resistance of the vault; this was further supported by numerical homogenised models presented by Milani and Lourenço (2013). This evidence supports the idea that the elliptical intersection arches are critical in hinge formation.

Figure 8 shows the force-moment interaction diagram for the critical areas where the thrust line is furthest away from the arch centreline in Figure 7. Figure 8 shows that global deformations in the shell introduce significant moments with relatively low membrane forces. The points closest to the

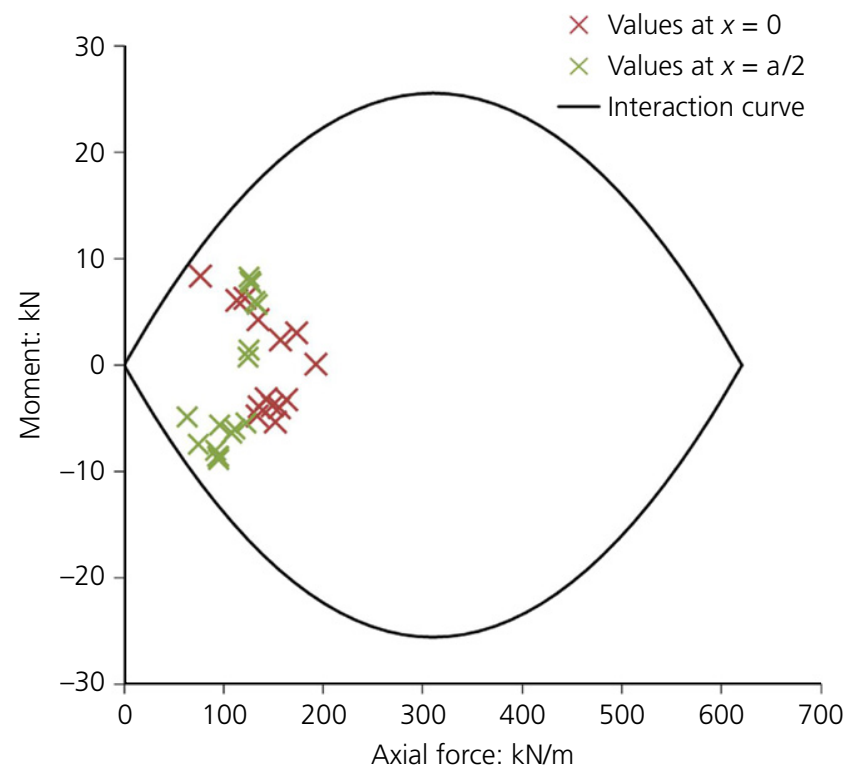

Figure 8. Rigid-plastic interaction diagram. A full-colour version of this figure can be found on the ICE Virtual Library (www. icevirtuallibrary.com) interaction curve correspond to the areas closest to the elliptical intersections between vault quadrants, suggesting that this is where hinges are most likely to form. A non-linear FE analysis was carried out (Section 4.2) in order to further investigate the failure mechanism of the vault and stress redistribution after the first hinge formation.

\subsection{Non-linear FE analysis}

A non-linear FE analysis was conducted to assess the ultimate load and failure mode. A damage-plasticity model was used to consider the non-linear properties of the masonry. In this model, the initial response of the masonry under compressive loading was assumed to be linear elastic until the yield stress was reached.

Tests on clay brick masonry (Kaushik et al., 2007a, 2007b) have shown that the behaviour of masonry in compression is linear elastic up to approximately one third of the compressive strength of the masonry (combined properties of bricks and mortar). Above this stress, cracks begin to form in the masonry, which introduces non-linearity. This was taken into account in the damage-plasticity model by setting the elastic limit as one third of the compressive strength of the masonry, as assumed by Milani et al. (2014).

For simplicity, the backfill was excluded from the FE analysis of the quadripartite vault, which could lead to capacity predictions on the conservative side. Backfill can have a stabilising effect, with the interaction between the masonry and the backfill material leading to increased load capacity (Milani and Lourenço, 2012). However, as found by Cavicchi and Gambarotta (2005), failure by hinge formation can still occur even if the ductility of the masonry is limited by the presence of backfill. The backfill can either be modelled as an equivalent horizontal pressure or included in the FE model directly, which gives more accurate results since the collapse pressure increases as the tensile strength of the backfill increases (Milani et al., 2014).

A tensile strength, $f_{\mathrm{t}}$, of $10 \%$ of the masonry compressive strength was considered in the FE model. The main properties in the plastic FE model are summarised in Table 3. The

Table 3. Properties applied in the plastic FE model

\begin{tabular}{lc} 
Property & \\
\hline Angle of dilation, $\phi_{\mathrm{d}}$ & $30^{\circ}$ \\
Flow potential eccentricity, $\varepsilon$ & $0 \cdot 1$ \\
Viscosity parameter, $\mu$ & $0 \mathrm{~s}$ \\
Initial equi-biaxial compressive yield stress/initial & $1 \cdot 16$ \\
uniaxial compressive yield stress, $\sigma_{\mathrm{bo}} / \sigma_{\mathrm{c} 0}$ & \\
Ultimate compressive strength, $f_{\mathrm{c}}$ & $1.9 \mathrm{~N} / \mathrm{mm}^{2}$ \\
Compressive yield strength, $f_{\mathrm{cy}}$ & $0.6 \mathrm{~N} / \mathrm{mm}^{2}$ \\
Ultimate tensile strength, $f_{\mathrm{t}}$ & $0.19 \mathrm{~N} / \mathrm{mm}^{2}$ \\
Poisson's ratio, $v$ & 0
\end{tabular}


constitutive material model used in the non-linear FE analysis was a damage-plasticity model based on uniaxial behaviour with the non-linear stress-strain relationship for tension and compression shown in Figure 9. The tensile response adopted was linear elastic followed by an exponentially decaying softening after cracking. For compressive behaviour, the initial response was assumed to be linear elastic up until the yield strength, $f_{\mathrm{cy}}$. There is then a phase of strain softening due to degradation after the material has yielded but before the ultimate compressive strength, $f_{\mathrm{c}}$, has been reached. After this point strain softening occurs as the stresses of the masonry decrease but the strains continue to increase. In Figure $9, d_{\mathrm{c}}$ and $d_{\mathrm{t}}$ are damage variables, which are functions of the plastic strains, temperature and field variables (DSS Simulia, 2012).

An incremental-iterative non-linear FE analysis was carried out. The results from this analysis are shown in Figure 10(a), which indicates that the structure behaved almost linear elastically until a load of approximately $5 \mathrm{kN} / \mathrm{m}^{2}$. Figure 10 (b) shows that this load corresponds to the formation of the first plastic deformations at the base of the intersection elliptical arches; this is further demonstrated in Section 5 with a 2D frame analysis. For loads above $5 \mathrm{kN} / \mathrm{m}^{2}$, plastic deformations continued propagating at the base and the areas at the intersection of the elliptical arches at mid-height became more critical.

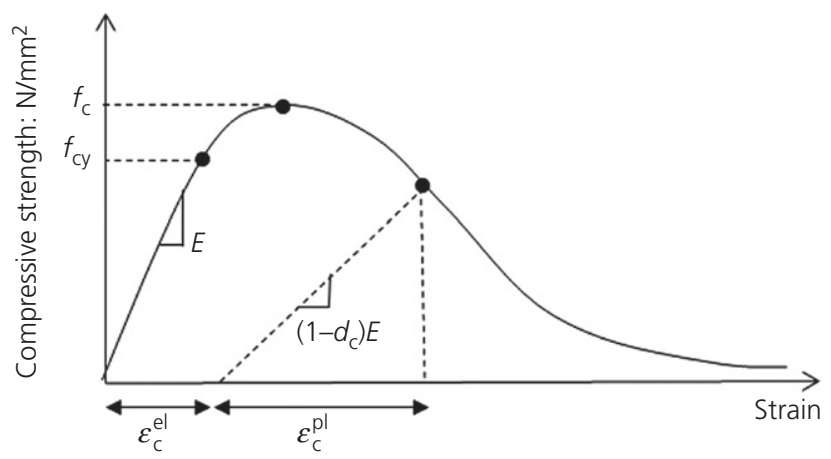

(a)

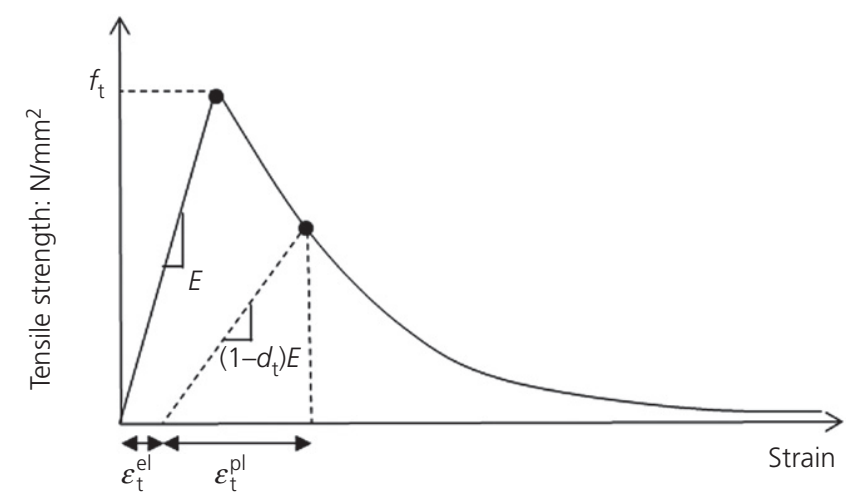

(b)

Figure 9. Non-linear stress-strain curves utilised in the non-linear FE analysis for compression (a) and tension (b) (DSS Simulia, 2012)
This is shown in the interaction diagram (Figure 10(c)) showing points around the elliptical arch at different heights for a load of $8 \mathrm{kN} / \mathrm{m}^{2}$. The failure load obtained numerically was verified using limit analysis (the constant value shown in Figure 10(a)). The limit analysis was based on a 2D approach, which is further described in Section 5.2 including the derivation of Equation 7 to assess the failure load.

\section{Two-dimensional analysis of elliptical intersection}

The 3D FE non-linear analysis shown in the previous section indicated that the behaviour of the quadripartite vault was governed by the development of plastic hinges at the elliptical arches at the intersection of the semi-cylindrical surfaces. In this section, a 2D elastic FE analysis of the elliptical intersection is presented to verify the load at which the first hinge developed according to the 3D FE damage-plasticity model. Furthermore, a limit analysis based on the upper-bound solution is presented in Section 5.2 for the 2D elliptical arch to verify the solution obtained from the 3D FE damage-plasticity model.

\subsection{Load definition and cross-sectional properties}

The vertical load applied to the elliptical intersection arches is obtained from the vertical projection of the hoop membrane force, $N_{\theta}$, acting on each of the vault quadrants, as shown in Figure 11(a). Since each rib will be carrying load from either side, this must be multiplied by two to give the total vertical load acting on each rib

\section{3. $N_{\theta, \mathrm{v}}=-2 w a \cdot \cos \theta \sin \theta$}

Thus, when $\theta=0$ or $90^{\circ}$, there will only be horizontal thrusts acting on the ribs. For all remaining values of $\theta$ there will be an elliptical distribution of loads acting on the ribs, as shown in Figure 11(b).

As discussed in Section 4.1, a plastic hinge is most likely to form at the elliptical intersection between vault quadrants. The moment required to cause a plastic hinge can be calculated using

4. $\quad M_{\mathrm{P}}=\frac{d^{3} f_{\mathrm{c}}}{24}$

5. $d=\sqrt{2} t$

where $d$ is the depth of the intersection between the brickwork quadrants as shown in Figure 12(a) and the plastic stress block assumed in the analysis is shown in Figure 12(b). A constant cross-section was adopted for the elliptical arches based on 


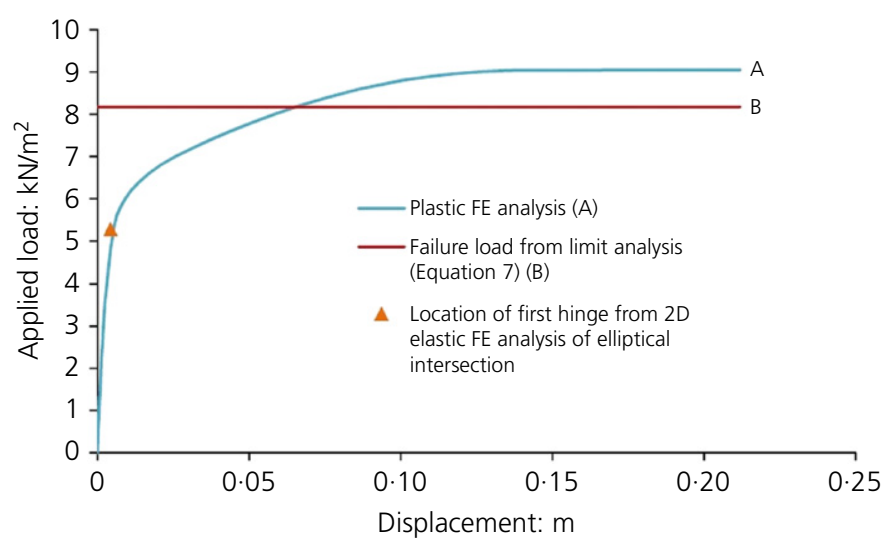

(a)
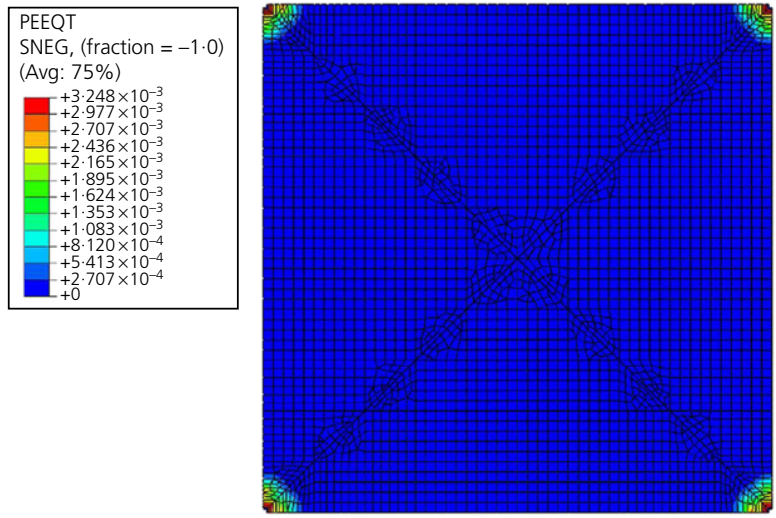

(b)

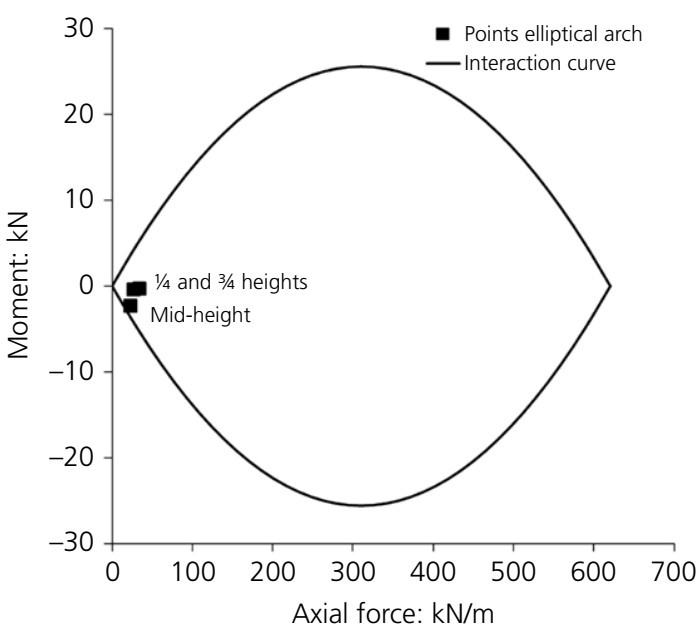

(c)

Figure 10. Results from initial plastic FE analysis with Poisson's ratio equal to zero and excluding the effect of the presence of ribs or horizontal restraint: (a) load-displacement curves; (b) plastic strains at a load of $5 \mathrm{kN} / \mathrm{m}^{2}$; (c) interaction diagram for points near elliptical arch at different heights at load of $8 \mathrm{kN} / \mathrm{m}^{2}$. A full-colour version of this figure can be found on the ICE Virtual Library (www. icevirtuallibrary.com)

the average section defined at mid-height $\left(\theta=45^{\circ}\right)$ shown in Figure 12.

The 2D elliptical arch elastic analysis indicated that the maximum moment acted at the base of the rib and the first hinge formed when the applied load was equal to $5 \cdot 3 \mathrm{kN} / \mathrm{m}^{2}$. The corresponding deflection at the top of the vault was $4.4 \mathrm{~mm}$. This load-deflection point is plotted on Figure 10 and shows that the first hinge from this model was very close to the point at which the masonry structure began to behave plastically according to the 3D FE damage-plasticity model.

\subsection{Limit analysis based on the upper-bound solution}

A kinematic analysis was carried out to verify the failure load predicted by the 3D FE damage-plasticity model. The single rib model and the complete vault model both show that the first hinge formed at the base of the ribs, followed by hinges on either side of the vault at mid-height (angle of around $30^{\circ}$ to the horizontal), as shown in Figures 10(c) and 13.

Half of one of the elliptical arches was considered, and the elliptical load shown in Figure 11(b) was distributed, for simplicity, into five discrete point loads. The collapse mechanism shown in Figure 13 was assumed. The mechanism consists of two segments - an outer segment with centre of rotation around the support (hinge 1) with rotation $\theta_{1}$ and an inner segment with centre of rotation around point $\mathrm{C}$ with rotation $\theta_{2}$, as shown in Figure 14.

The exact location of hinge 2 in the mechanism can be obtained from a parametric limit analysis or alternatively from the 3D FE damage-plasticity model results which indicated that hinge 2 formed roughly around $30^{\circ}$ from the horizontal. For the location of hinge 2 at $30^{\circ}$ (mid-height in an elliptical 


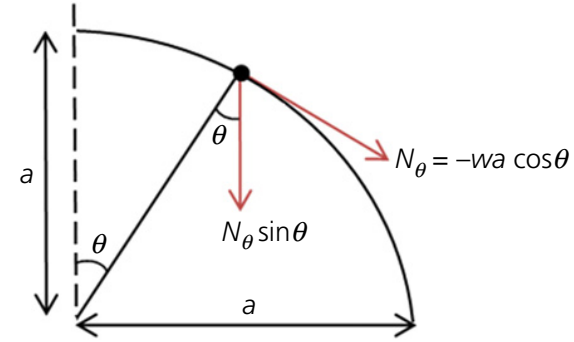

(a)

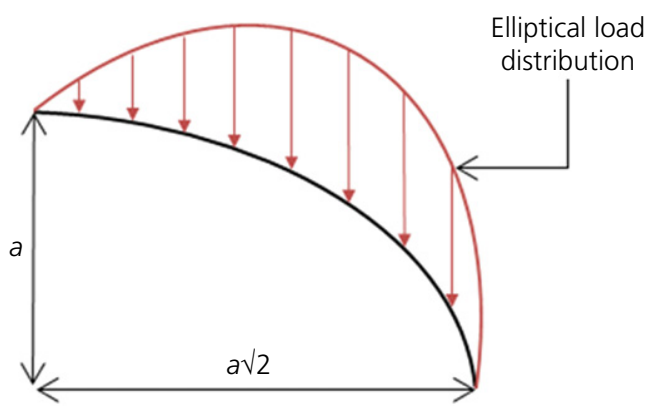

(b)

Figure 11. (a) Resolving axial force into horizontal and vertical components. (b) Resulting elliptical load distribution on the ribs

arch) it can be demonstrated from geometric conditions that $\theta_{1}=\theta_{2}$. The external work is calculated in terms of $\theta_{1}$ for each of the loads $\lambda_{1} P_{1}$ to $\lambda_{5} P_{5}$, as shown in Figure 14 for $\lambda_{2} P_{2}$. As an example, Table 4 shows the calculations needed for the external work corresponding to $\lambda_{2} P_{2}$, given by

6. $E=\lambda_{2} P_{2} \theta_{1}(a \sqrt{2}) / 3$

The total external work was found to be equal to $0 \cdot 185 \mathrm{wa}^{3} \theta$ and the internal work dissipated was equal to $3 M_{\mathrm{P}} \theta$ where $\theta=\theta_{1}=\theta_{2}$. Equating the internal and external work gives the following equation for the failure load of the vault

7. $w=\frac{600 M_{\mathrm{p}}}{37 a^{3}}$

Using Equation 7, the failure load for the quadripartite vaults at London Bridge station was calculated to be $8.2 \mathrm{kN} / \mathrm{m}^{2}$. This is approximately $10 \%$ lower than the failure load predicted by the 3D plastic FE analysis, which is on the safe side as shown in Figure 10. The small differences in the results can be explained by the discretisation of the elliptical load applied across the vault into point loads and the assumption that the entire load was transferred to the intersection between the vault quadrants. Moreover, the failure load is likely to be larger than this in reality as the backfill will have a stabilising effect, as discussed in Section 4.2.

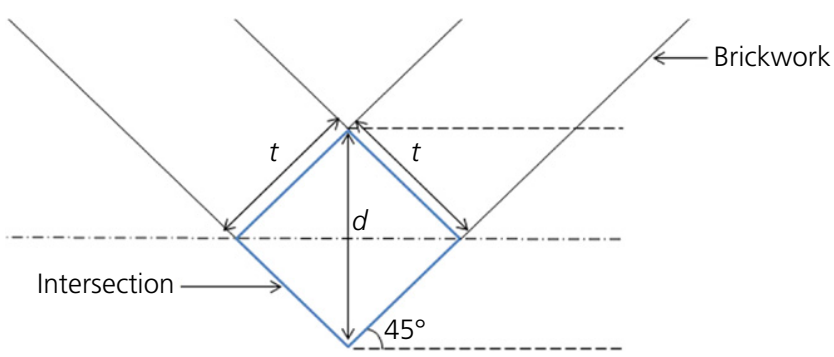

(a)

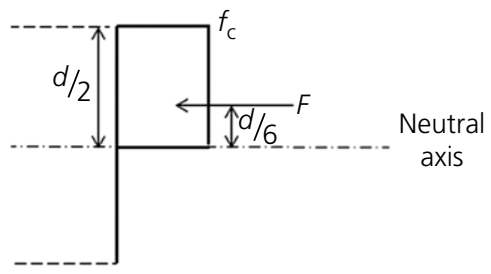

(b)

Figure 12. (a) Assumed shape of intersection between membranes. (b) Stress block assumed for the plastic moment

\section{Quadripartite vault under non-symmetrical conditions}

6.1 Influence of horizontal restraints

With the 3D plastic FE model verified and found to give very similar results to the limit analysis, it was applied to represent the boundary conditions for the vaults at London Bridge station. The vault experiencing the highest loading from construction of the new viaduct is highlighted in Figure 15, showing the grid of vaults in the undercroft of the station. Some of these vaults will be demolished and replaced with reinforced concrete vaults. More information on the scheme is given by Hicks (2015).

The vault under the largest load is restrained from horizontal movement by the surrounding quadripartite vaults on three sides and a barrel vault on the fourth side. The boundary conditions were modified to take this into account by restraining all the nodes at the four edges of the vault from horizontal movement. The mechanical properties of the vaults were identical to those described in Tables 2 and 3, with the only difference being that a Poisson's ratio of 0.25 was adopted in this case. The results from this analysis are shown in Figure 16.

The analysis was first completed without ribs and without any horizontal restraint, with the only support provided at the base of the structure. The results of this analysis are also included in Figure 16(a), which shows that including the confining effect of the surrounding vaults increased the failure load by approximately $30 \%$. Therefore, where quadripartite vaults are found in grids with adjacent vaults providing horizontal restraint, Equation 7 will provide a conservative estimate of the failure load. Figure 16(a) shows that, for a load of around 


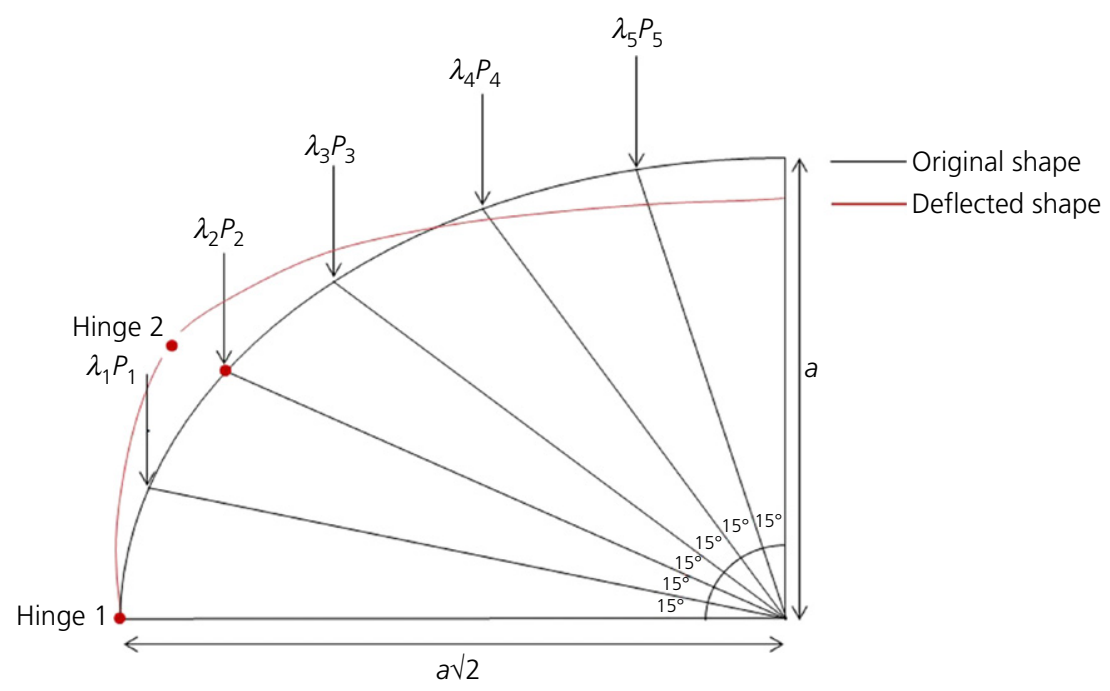

Figure 13. Assumed collapse mechanism of elliptical arch

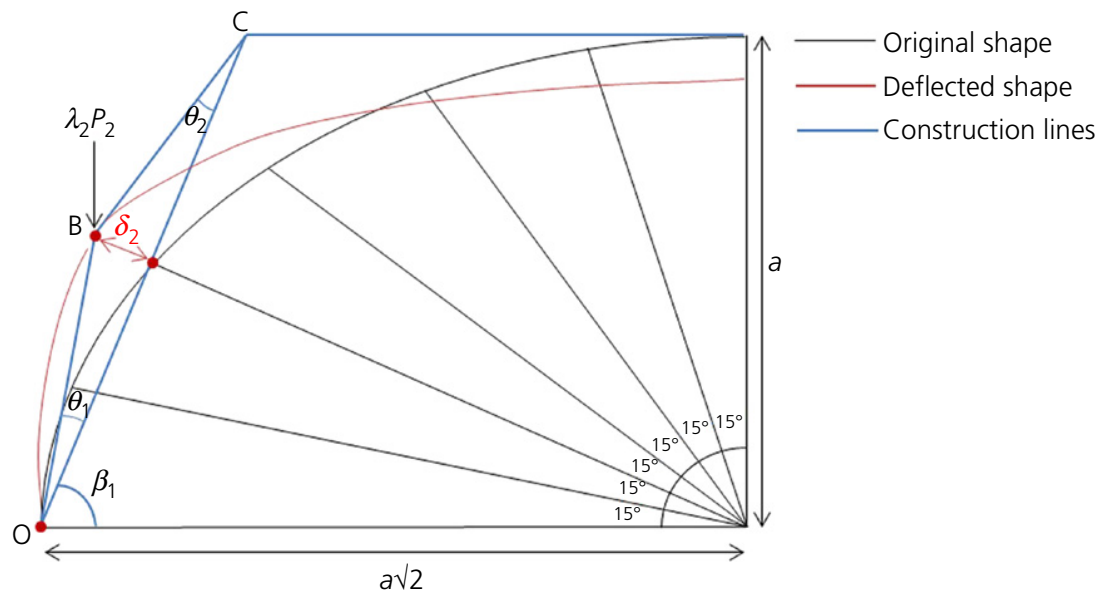

Figure 14. Example of external work calculation for discrete load $\lambda_{2} P_{2}$

$8 \mathrm{kN} / \mathrm{m}^{2}$ (failure load of unrestrained case), the vertical deflections in the restrained case were negligible; the plastic strains obtained in the shell elements in the non-linear FE analysis were zero for this load. For a higher load of around $12 \mathrm{kN} / \mathrm{m}^{2}$, Figure 16(b) shows that plastic strains had fully developed at

Table 4. Example calculations for external work corresponding to $\lambda_{2} P_{2}$

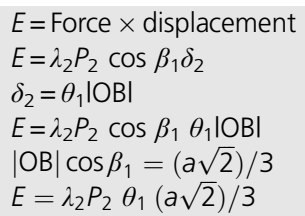

the supports (first hinge) whereas points at around mid-height were becoming more critical (shown by the points near the interaction curve in Figure 16(c)).

\subsection{Influence of the presence of ribs}

The presence of ribs at the intersection between the semicylindrical surfaces influences the capacity of the structure. This effect was modelled in the 3D FE analysis by including frame elements at the intersection; the properties are shown in Table 5. The frame elements were connected to the shell elements at 11 discrete points equally spaced along the intersection between the semi-cylindrical surfaces, as shown in Figure 4. Unfortunately, test results were not available for the limestone so its properties were estimated from a visual inspection and guidance provided by Bell (2007). 


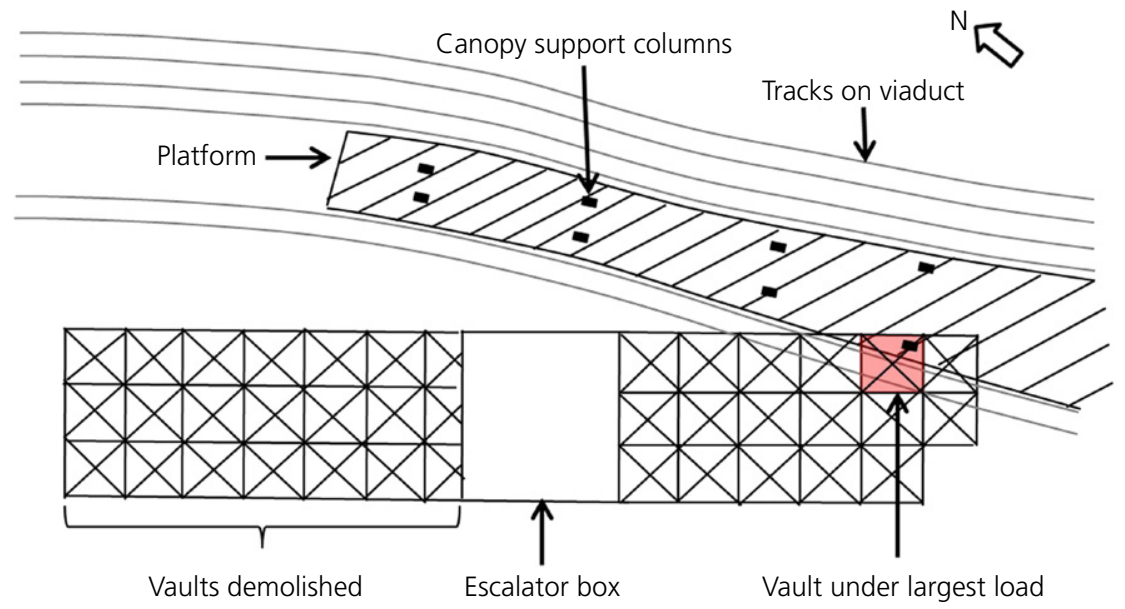

Figure 15. Location of the vault under the largest load

The response of the limestone was assumed to be linear elastic until $f_{\mathrm{c}}$ was reached. In this analysis, it was assumed that the ribs would remain in the elastic region under the applied loads according to the force-moment interaction diagram of the cross-section.

The load acting on the FE model was increased incrementally until failure was predicted, as shown in Figure 17(a). The failure load considering the ribs increased substantially compared with that for the vault without ribs. These results clearly support the proposal that strengthening the elliptical intersection arches is an effective approach of retrofitting the structure, as shown by Milani et al. (2014), and that the proposed 2D analysis is an effective tool.

Figure 17(a) shows that the design load from Table 1 is much lower than the ultimate capacity of the vault with ribs when horizontal movement is restrained. To verify the results from Figure 17(a) for the case without horizontal restraint, a 2D limit analysis with an increased cross-section taking into account the presence of the ribs was conducted.

The compressive strength of the limestone was estimated to be $40 \mathrm{~N} / \mathrm{mm}^{2}$. Using this value with a depth of $330 \mathrm{~mm}$, Equation 4 predicts the plastic moment capacity of the ribs to be $114.3 \mathrm{kNm}$. Equation 7 was then used to calculate the failure load, which was determined to be $115 \cdot 7 \mathrm{kN} / \mathrm{m}^{2}$. This is approximately $8 \%$ larger than the failure load predicted by the FE analysis.

When the ribs were included in the analysis the structure was much stiffer and therefore the influence of lateral restraint on the capacity will be much higher. A comparison of Figures 16(a) and 17(a) shows that including horizontal restraint has a much larger impact when the ribs are included in the model, with the failure load increasing by approximately
$125 \%$ for the case with ribs. In such cases, a more refined model including the surrounding structure will be needed in order to assess the level of horizontal restraint more accurately.

Figure 17(b) shows the plastic strains in the horizontally restrained case with ribs for a load of around $100 \mathrm{kN} / \mathrm{m}^{2}$ (value close to the design load); strains are concentrated at discrete points where the rib frame elements are connected to the shell elements. These results could be smoothed out by increasing the number of divisions in the elliptical intersection ribs. The moments obtained in the frame elements indicated that, for a load of $100 \mathrm{kN} / \mathrm{m}^{2}$, the first hinge had fully developed at the base for both restrained and unrestrained cases. For this load, Figure 17(c) shows the interaction diagram for the shell elements at the elliptical intersection at mid-height; the figure shows that, for the unrestrained case, the second hinge had almost fully developed whereas this was not the case for the restrained situation. The results shown in Figure 17 indicate that the global response is highly influenced by what happens at the elliptical intersection, as assumed in the proposed 2D approach. Alternatively, more sophisticated numerical modelling could be adopted by explicitly considering the horizontal restraints and the shell-rib interface by using solid elements (Milani and Lourenço, 2012).

\section{Conclusions}

Quadripartite vaults are often found below ground level and are therefore susceptible to load increases due to changes in land use above the structure. A new formula for predicting the ultimate capacity of a quadripartite vault has been presented in this paper. This formula can be used in practice to predict the strength of existing masonry vaults. The approach is suitable for quadripartite vaults with or without ribs; the presence of ribs is taken into account by modifying the cross-section at 


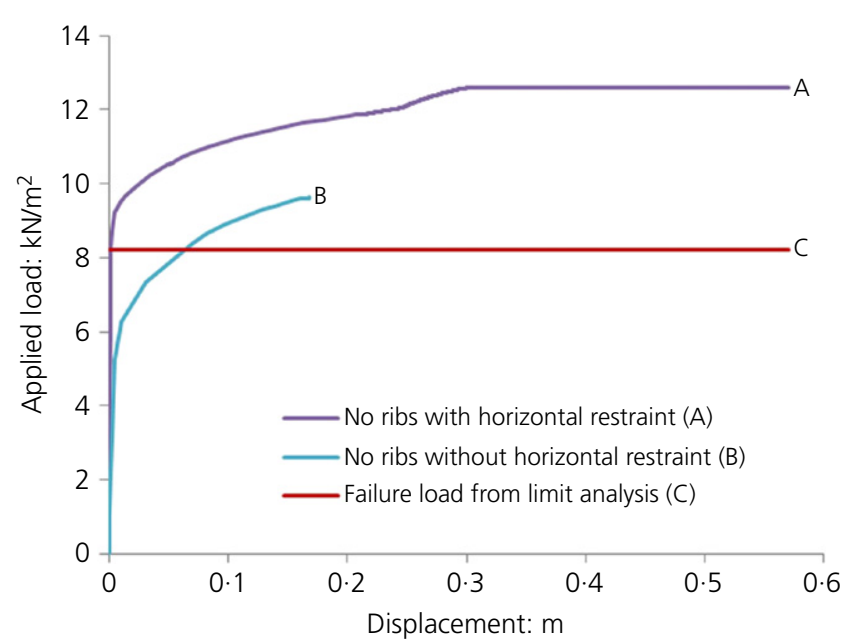

(a)
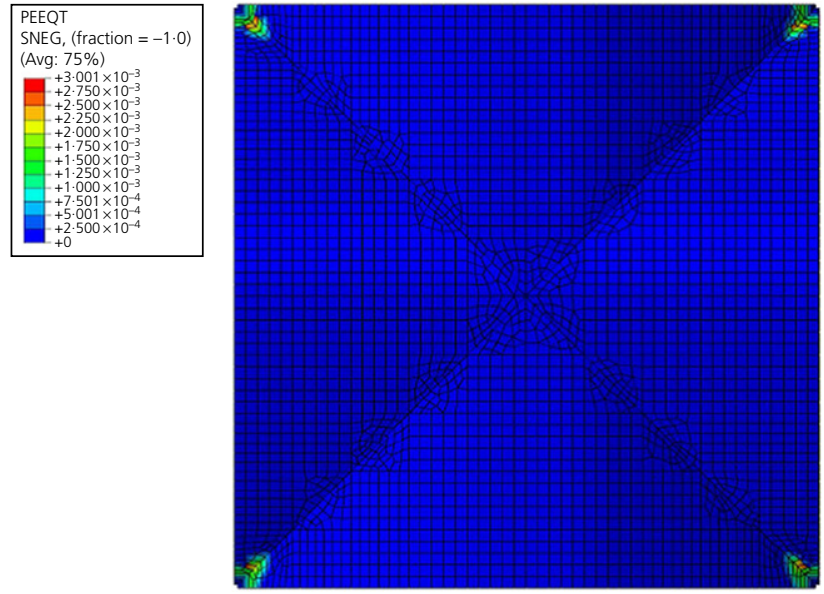

(b)

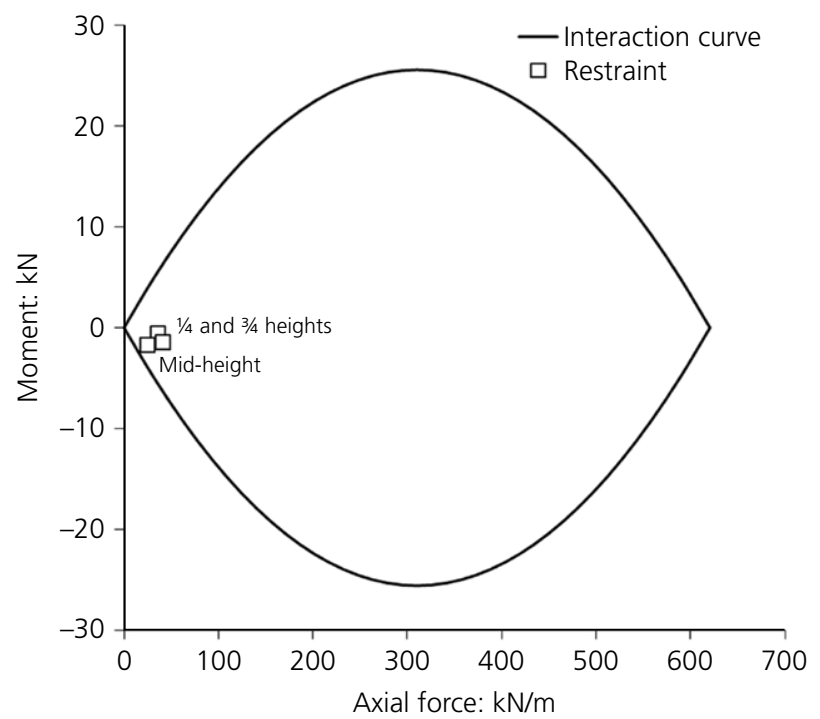

(c)

Figure 16. Influence of horizontal restraint in vaults without ribs: (a) load-displacement curves; (b) plastic strains in the restrained case at a load of around $12 \mathrm{kN} / \mathrm{m}^{2}$ well after development of the first hinge; (c) interaction diagram for restrained case with points corresponding to a load of $12 \mathrm{kN} / \mathrm{m}^{2}$ at different heights along the elliptical intersection. A full-colour version of this figure can be found on the ICE Virtual Library (www.icevirtuallibrary.com)

Table 5. Properties of blockwork ribs

\begin{tabular}{ll}
\hline Property & \\
\hline Thickness, $t$ & $330 \mathrm{~mm}$ \\
Width, $W$ & $210 \mathrm{~mm}$ \\
Young's modulus, $E$ & $40000 \mathrm{~N} / \mathrm{mm}^{2}$ \\
Compressive strength, $f_{\mathrm{c}}$ & $40 \mathrm{~N} / \mathrm{mm}^{2}$ \\
Density, $\rho$ & $25 \mathrm{kN} / \mathrm{m}^{3}$ \\
Poisson's ratio, $v$ & $0 \cdot 26$
\end{tabular}

the intersection of the vault quadrants and using this to calculate the plastic moment capacity. The following conclusions were drawn from this work. (a) The proposed equation for the ultimate capacity, derived from limit analysis of the 2D elliptical intersection arches, can be used to predict the failure load of a quadripartite vault provided that the load is uniformly distributed and the structure is only supported at its base.

(b) In the cases investigated in this work, the FE analysis utilising a damage-plasticity model for the properties of the masonry produced results comparable to the limit analysis; the results from the FE analysis were approximately 10\% higher when ribs were not included and $8 \%$ lower when ribs were included. 

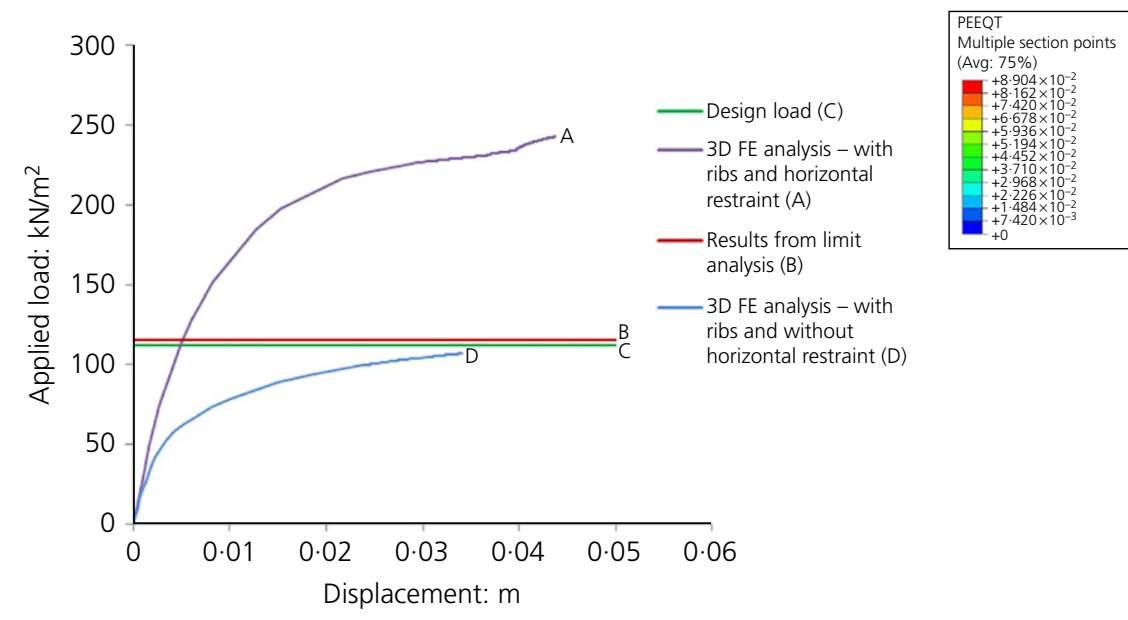

(a)

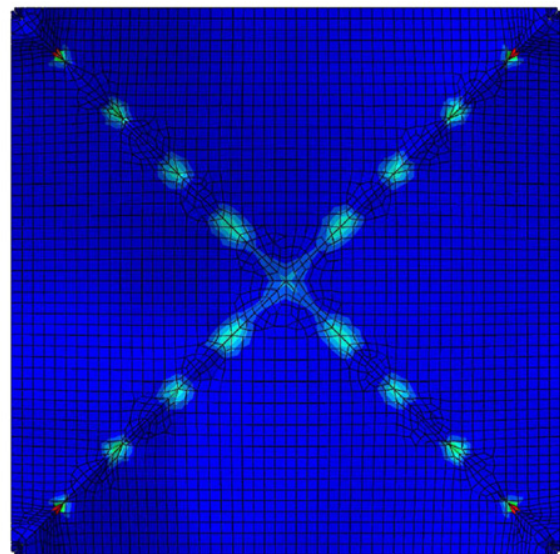

(b)

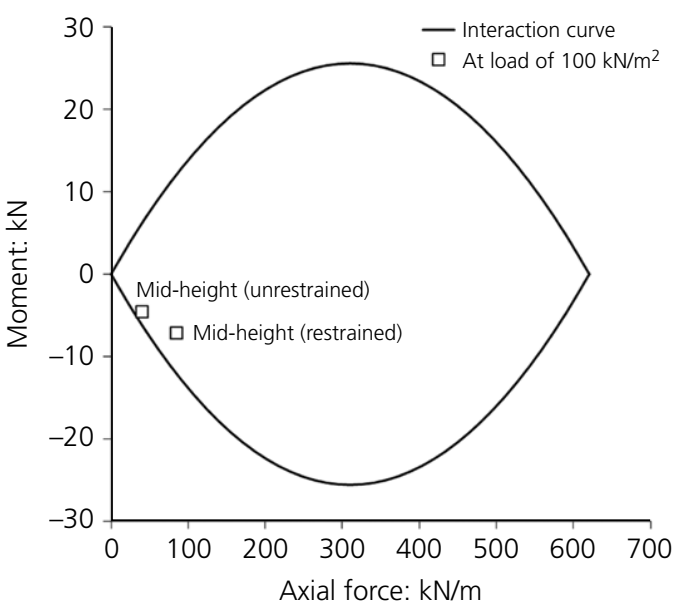

(c)

Figure 17. Influence of horizontal restraint in vaults with ribs: (a) load-displacement curves; (b) plastic strains in the restrained case at a load of around $100 \mathrm{kN} / \mathrm{m}^{2}$; (c) interaction diagram for restrained case with points corresponding to a load of $100 \mathrm{kN} / \mathrm{m}^{2}$ at mid-height of the elliptical intersection for the restrained and unrestrained cases. A full-colour version of this figure can be found on the ICE Virtual Library (www.icevirtuallibrary.com)

(c) Introducing horizontal restraint to take into account the effect of adjacent vaults was found to lead to a strength increase in vaults with and without ribs. For vaults without ribs, restraining the edges of the vault from horizontal movement increased the capacity by approximately $30 \%$ according to the $3 \mathrm{D}$ FE damage-plasticity model. When ribs were included, the structure was much stiffer and the increase in strength due to horizontal confinement was much larger; therefore, a more refined analysis to quantify the horizontal restraint provided by surrounding structures is needed.

(d) The case study of London Bridge station showed that the presence of ribs had the largest effect on the strength of the vault. Further work may look into quantifying the effect of strengthening the ribs in terms of an increase of load.
The proposed formula provides reasonable predictions of the failure load of simply supported quadripartite vaults under idealised uniformly distributed gravity loads. The proposed approach is based on the upper-bound limit solution of plasticity and therefore alternative failure mechanisms should be examined in design to avoid premature local failure (e.g. failure of the cylindrical shell due to concentrated loads, damaged masonry or geometrical imperfections). In addition, the influence of backfill and lateral restraints can enhance the response and this should be investigated further, numerically and experimentally, for specific cases.

\section{REFERENCES}

ABL (Alan Baxter Ltd) (2011) London Bridge Station Structural Investigations: Interpretative Report. Network Rail, London, UK. Bell F (2007) Engineering Geology, 2nd edn. Butterworth-Heinemann, Oxford, UK. 
BSI (2002) BS EN 1990:2002: Eurocode - Basis of structural design. BSI, London, UK.

BSI (2007) UK NA to BS EN 1996-1-1:2005: UK National Annex to Eurocode 6: Design of masonry structures - part 1-1: general rules for reinforced and unreinforced masonry structures. BSI, London, UK.

BSI (2009) BS EN 1996-1-1:2005: Eurocode 6 - Design of masonry structures - part 1-1: general rules for reinforced and unreinforced masonry structures (incorporating corrigenda February 2006 and July 2009). BSI, London, UK.

Cavicchi A and Gambarotta L (2005) Collapse analysis of masonry bridges taking into account arch-fill interaction. Engineering Structures 27(4): 605-615.

Creazza G, Saetta A, Matteazzi R and Vitaliani R (2000) Analyses of masonry vaulted structures by using 3-D damage model. Proceedings of the European Congress on Computational Methods in Applied Sciences and Engineering, Barcelona, Spain.

DSS Simulia (2012) Abaqus Analysis User's Manual (6.12). DSS Simulia, Providence, RI, USA.

Foraboschi P (2004) Strengthening of masonry arches with fiber-reinforced polymer strips. Journal of Composites for Construction, ASCE 8(3): 191-202.

Heyman J (1966) The stone skeleton. International Journal of Solids and Structures 2(2): 249-279.

Heyman J (1995) The Stone Skeleton. Cambridge University Press, Cambridge, UK.

Hicks M (2015) The quadripartite vaults at London Bridge station. The Structural Engineer 93(6): 12-14.
Huerta S (2008) The analysis of masonry architecture: a historical approach. Architectural Science Review 51(4): 297-328.

Kaushik H, Rai D and Jain S (2007a) Stress-strain characteristics of clay brick masonry under uniaxial compression. Journal of Materials in Civil Engineering 19(9): 728-739.

Kaushik H, Rai D and Jain S (2007b) Uniaxial compressive stress-strain model for clay brick masonry. Current Science 92(4): 497-501.

Milani G and Lourenço PB (2012) 3D non-linear behaviour of masonry arch bridges. Computers and Structures 110-111: 133-150, https://doi.org/10.1016/j.compstruc.2012.07.008.

Milani G and Lourenço PB (2013) Simple homogenized model for the nonlinear analysis of FRP-strengthened masonry structures. II: structural applications. Journal of Engineering Mechanics 139(1): 77-93.

Milani G, Simoni M and Tralli A (2014) Advanced numerical models for the analysis of masonry cross vaults: a case study in Italy. Engineering Structures 76: 339-358, https://doi.org/10.1016/ j.engstruct.2014.07.018.

O'Dwyer D (1999) Funicular analysis of masonry vaults. Computers \& Structures 73(1-5): 187-197.

Taylor WMR (1982) The technology of transition: sexpartite to quadripartite vaulting in high gothic architecture. The Art Bulletin 64(4): $579-587$.

Tony Gee and Partners (2011) Structural Investigation Interpretative Report. Internal report commissioned from TG\&P by the Infrastructure Investment of the Thameslink Programme, Esher, UK.

\section{How can you contribute?}

To discuss this paper, please email up to 500 words to the editor at journals@ice.org.uk. Your contribution will be forwarded to the author(s) for a reply and, if considered appropriate by the editorial board, it will be published as discussion in a future issue of the journal.

Proceedings journals rely entirely on contributions from the civil engineering profession (and allied disciplines). Information about how to submit your paper online is available at www.icevirtuallibrary.com/page/authors, where you will also find detailed author guidelines. 